\title{
Considerações sobre uma avaliação diagnóstica do conceito de função à luz da Teoria dos Registros de Representações Semióticas
}

\section{Considerations about a diagnostic evaluation of the concept of function in light of the Theory of Semiotic Representations}

\author{
Lidiane Pereira Carvalho \\ $\underline{\text { lidiane.p.carvalho@gmail.com }}$ \\ José Ayron Lira dos Anjos \\ ayronanjos@gmail.com \\ Severino Barros de Melo \\ sbmelo55@gmail.com
}

\begin{abstract}
Resumo
Este trabalho é um recorte de uma pesquisa de mestrado cujo objetivo é elaborar, aplicar e validar uma situação didática para o conceito de função com base na Teoria dos Registros de Representações Semióticas. Este artigo apresenta os resultados das questões em língua natural de uma avaliação diagnóstica realizada com estudantes do $1^{\text {o }}$ ano do Ensino Médio de um Campus do IFPE que foram o público da pesquisa. Os dados foram analisados qualitativamente e apontam que muitos estudantes exigem uma lei algébrica para que uma relação seja função e que as ideias de relação, dependência e variação são as mais presentes na concepção de função desses estudantes.
\end{abstract}

Palavras-chaves: Representações semióticas; Função; Ensino.

\begin{abstract}
This work is a cut of a master's research whose objective is to elaborate, apply and validate a didactic situation for the concept of function based on the Theory of Semiotic Representations Records. This article presents the results of the questions in the natural language of a diagnostic evaluation carried out with students of the $1^{\text {st }}$ year of High School of an IFPE Campus who were the public of the research. The data were analyzed qualitatively and indicate that many students demand an algebraic law for a relation to be a function and that the ideas of relation, dependence and variation are the most present in the conception of function of these students.
\end{abstract}

Keywords: Semiotic representations; Function; Teaching.

\section{Introdução}

A matemática é muitas vezes considerada como uma disciplina difícil; índices governamentais apontam que, em 2013, apenas 9,3\% dos estudantes brasileiros concluíram o $3^{\circ}$ ano do Ensino Médio com o nível de proficiência adequado em matemática (TODOS PELA EDUCAÇÃO, 2015). Tal resultado evidencia a necessidade de discutir, pesquisar e repensar a forma como a matemática é ensinada, de modo que ela possa ser compreendida como uma construção humana importante para a formação dos jovens e para a compreensão do mundo (BRASIL, 2002). 
Para isso, precisamos adotar um ensino que busque promover a compreensão dos conceitos de forma que os estudantes possam refletir e argumentar criticamente frente a problemas que envolvam matemática e não apenas memorizar informações.

Em busca de alternativas para um ensino pautado em memorizações, muitas vezes decorrentes do entendimento equivocado do que seria aprender, encontramos a Teoria dos Registros de Representações Semióticas (DUVAL, 2009, 2010, 2015). Acreditamos que essa teoria pode contribuir para esse estudo, dado que ela aponta e discute as atividades cognitivas envolvidas e indispensáveis para o processo de ensino e aprendizagem, destacando o papel das representações semióticas para a aprendizagem matemática.

Duval (2012) destaca que a importância do estudo das representações semióticas para a matemática se deve à natureza da própria matemática, pois diferentemente de outras ciências seus objetos de estudo não podem ser alcançados diretamente, sendo por isso necessária a utilização de representações semióticas. Mas, é importante compreender que os objetos matemáticos não se limitam a suas representações, pois diferentes registros podem representar um mesmo conceito, mas cada registro favorece características diferentes, tornando imprescindível o uso articulado das diversas representações para uma melhor compreensão. Quanto maior a diversidade de representações semióticas maiores serão as condições para uma real aprendizagem dos conceitos matemáticos, dada a grande dificuldade em explorar todas as características de um conceito por meio de uma única representação. $\mathrm{O}$ estudo de múltiplas representações pode permitir ao aprendiz uma visão mais completa do conteúdo permitindo-lhe expressá-lo através de suas próprias palavras, realizando inferências com aprendizados anteriores, sejam eles escolares ou não, evitando a memorização excessiva de fórmulas e uma real compreensão do conceito matemático.

Assim, defendemos que a utilização de diferentes registros semióticos contribui para o aprendizado de novos conceitos e para o aprofundamento cognitivo de conceitos já conhecidos, possibilitando aos estudantes compreender os conceitos ao invés de decorar fórmulas ou procedimentos sem sentido.

\section{A Teoria dos Registros de Representações Semióticas}

A linguagem é o meio pelo qual o homem expressa seus pensamentos, organiza informações sociais, culturais e/ou científicas, e as relaciona por meio de signos e estruturas lógicas. O próprio funcionamento cognitivo depende de registros e signos: é através da internalização deles que desenvolvemos as representações mentais, realizamos diferentes funções cognitivas e produzimos novos conhecimentos (DUVAL, 2012). 
A Teoria dos Registros de Representações Semióticas desenvolvida por Raymond Duval $(2009,2011)$ aponta para a necessidade e importância das representações semióticas para o ensino e aprendizagem de matemática.

Duval (2015) explica que a matemática se diferencia de todas as outras formas de conhecimento e atividade por duas características cognitivas e epistemológicas: a possibilidade de desenvolvimento independente de fontes externas de informação e o poder ilimitado de exploração para geração de novos conhecimentos. Essas características se devem ao papel fundamental desempenhado pelas representações na matemática.

O estudo da história da matemática revela a importância das representações tanto pela sua grande variedade, quanto pelo papel que o seu desenvolvimento desempenhou para a evolução do pensamento matemático (DUVAL, 2010).

Entendemos assim que, para o aprendizado da matemática, é necessária a criação e utilização de representações. Todavia, é preciso ter um cuidado no processo de ensino, pois, segundo Duval (2009), não há compreensão na matemática enquanto não se é capaz de distinguir um objeto de sua representação. Um mesmo objeto matemático pode ser representado de diversas formas. O conceito de função, por exemplo, possui diversas representações, tais como diagramas, gráficos, expressões algébricas, língua natural e tabelas, tendo cada uma delas algumas vantagens e limitações de acordo com as características que destacam.

Justamente por essa pluralidade, as representações são secundárias ao aprendizado conceitual. A essência do aprendizado está nas transformações que podemos fazer nesses registros, que devem promover o aprendizado do objeto matemático representado, mas tais transformações dependem diretamente do tipo de registro utilizado e das atividades que esse registro possibilita.

Sendo assim, Duval $(2009,2011)$ explica que o sistema semiótico deve possibilitar a realização de três atividades cognitivas fundamentais para ser considerado um registro de representação semiótica: Formação, Tratamento e Conversão.

\subsection{As atividades cognitivas fundamentais}

A Formação consiste na criação de uma representação compreensível. Para isso, é necessária a escolha de um registro e dos dados e conteúdo que se deseja representar. Cada registro privilegia alguns dados em função de suas próprias regras (gramaticais, entraves de construção de figuras...) denominadas regras de conformidade (DUVAL, 2009, 2011). Essas regras são essenciais para garantir o reconhecimento da representação e permitir a realização 
dos tratamentos, além de definirem um sistema de formação. É importante compreender que a atividade de formação não se limita à aplicação das regras de conformidade, pois é na verdade um processo, e que o conhecimento das regras de conformidade não assegura a produção de um registro, visto que um sujeito é capaz de reconhecer um registro mesmo que não saiba criá-lo (DUVAL, 2012).

O Tratamento é uma transformação interna, isto é, a representação é modificada, mas o produto da transformação permanece no mesmo registro inicial. Essa atividade também possui regras próprias que podem ser específicas ou comuns a vários registros, estando em todo caso em concordância com as demais regras de tratamento específicas do registro utilizado (DUVAL, 2009, 2011). Por exemplo, temos a paráfrase na língua natural, o cálculo nas expressões numéricas e algébricas, a reconfiguração e anamorfose para as figuras.

A Conversão é uma atividade externa que mobiliza pelo menos dois registros: o registro de partida, onde será realizada a atividade de conversão, e um registro de chegada, no qual estará o produto da transformação, podendo o conteúdo ser conservado totalmente ou apenas em parte (DUVAL, 2009, 2011). Por exemplos: a ilustração, quando representamos por meio de uma imagem um texto e a descrição, que representa a conversão contrária. Não há, em geral, regras para conversão e, quando há uma regra, há ambiguidades e dificuldades para sua compreensão, além de que a mesma regra não serve nos dois sentidos de conversão - por exemplo, transformar a representação algébrica de uma função em gráfico, e converter o gráfico para sua representação algébrica requer métodos distintos - , o que implica em dificuldades e custos operacionais diferentes para cada caso.

Assim, as representações semióticas se caracterizam pela relatividade de cada registro e pela possibilidade de serem convertidas para outros sistemas semióticos, representando o mesmo objeto e, no entanto, tomando significações diferentes (DUVAL, 2009).

É importante saber distinguir essas três atividades, pois cada uma desempenha um papel e representa uma dificuldade no processo de aprendizagem conceitual. É comum que no ensino de matemática os processos de formação e tratamento sejam privilegiados em relação à conversão, fato que prejudica seriamente a aprendizagem conceitual, pois, como explica Duval (2012), na matemática as atividades nunca ficam limitadas a um registro - o que ocorre em alguns casos é que o processo de conversão acontece implicitamente, para antecipar resultados ou selecionar o melhor registro a ser utilizado, o que torna imprescindível a coordenação simultânea de vários registros. 
O desenvolvimento dos conhecimentos e os obstáculos referentes às representações semióticas perpassam três fenômenos: a diversificação dos registros de representação semiótica; a diferenciação entre o representante e o objeto representado, e a coordenação entre os diferentes registros (DUVAL, 2009). Assim, "as significações que formamos dos objetos matemáticos, por intermédio de relações triádicas, objeto, signo e interpretante, constituem um dinâmico processo de formação das noções em nossas mentes" (SOUZA, MORETTI, 2005, p. 74). A formação de conceitos está, assim, diretamente relacionada ao acesso a diferentes representações que permitam conhecer diferentes dados do conceito, transformá-los e descobrir suas propriedades, diferenciando-o de suas representações.

\section{Pesquisa acerca de Representações e conceito de função}

A primeira fase da pesquisa do mestrado consistiu na aplicação de um pré-teste composto por treze questões, abertas e fechadas, que englobaram a definição de função, avaliação e reconhecimento do conceito de função em diferentes representações (gráficos, expressões algébricas, língua natural, diagrama de flechas), a associação entre os registros gráfico, tabelar e algébrico e a conversão entre os registros gráficos e algébricos.

A análise dos dados buscou informações sobre as dificuldades, estratégias e representações mobilizadas no processo de compreensão do conceito de funções. As respostas de problemas e questões, comentários e anotações serão analisados qualitativamente por meio da análise textual discursiva (MORAES, 2003; MORAES E GALIAZZI, 2006).

O grupo de participantes da pesquisa foi composto por estudantes do $1^{\circ}$ ano do Ensino Médio de um Campus do Agreste do Instituto Federal de Pernambuco. Foram analisadas as atividades de 32 estudantes, que responderam pelo menos $50 \%$ das questões. Os participantes foram codificados aleatoriamente de $\mathrm{E}_{1}$ a $\mathrm{E}_{32}$, como não é do interesse da pesquisa realizar análise de gênero, todos os estudantes serão tratados no masculino para não gerar nenhum tipo de identificação.

A Análise Textual Discursiva é uma abordagem de análise de dados que transita entre a análise de conteúdo e a análise de discurso (MORAES e GALIAZZI, 2006). Apesar de ser uma análise de textos (produções escritas), Moraes (2003, p. 194) destaca que "o termo deve ser entendido num sentido mais amplo, incluindo imagens e outras expressões linguísticas", podendo ser empregada tanto para análise de documentos pré-existentes como documentos 
produzidos para a pesquisa - o conjunto de documentos que servirão de base para a pesquisa é denominado corpus (MORAES, 2003).

A Análise Textual Discursiva é composta por três etapas: a unitarização, que consiste na leitura dos textos e decomposição em unidades de análise definidas com base nos pressupostos teóricos; a categorização, que é o agrupamento das unidades de análise por meio de comparações em função dos referenciais teóricos, que podem ser: a) a priori, b) emergentes das informações analisadas, c) uma combinação de categorias a priori e emergentes, ou d) originar-se da intuição do pesquisador mediante a integração e autoorganização, objetivando uma visão holística; por fim, a última etapa é a captação de um novo emergente, que é a reformulação do texto para a comunicação das compreensões obtidas.

Nesta pesquisa, adotamos algumas categorias a priori mais abrangentes para análise das respostas aos problemas com base nas referências teóricas. São elas: representações mobilizadas; estratégias de solução; interpretação de enunciados; e as atividades cognitivas: formação, tratamento e conversão. Serão adotadas, ainda, categorias emergentes, bem como categorias a priori.

\section{Análise e resultados}

Será realizada a apresentação e análise de cada questão em língua natural e, depois, será apresentada uma análise comparativa dos resultados para esse registro.

$I^{a}$ questão: Defina o conceito matemático de função.

Optamos por iniciar a atividade questionando diretamente como os estudantes definem função. Consideramos que definir não é uma tarefa simples, em especial definir conceitos científicos, pois embora as definições costumem ser apresentadas na introdução dos conteúdos matemáticos, a prática do ensino nem sempre realiza um estudo sobre ela. Em geral, visa mais o estudo de problemas e situações que possibilitem aos estudantes construir um campo ou imagem conceitual do conteúdo, raramente sendo exigida dos estudantes uma definição formal do conceito. Consideramos então que mesmo estudantes que compreendem o conceito de função podem apresentar dificuldade na hora de defini-lo por não terem familiaridade com essa tarefa e domínio da linguagem científica necessária. Contudo, as respostas dos estudantes a essa questão, ainda que nem sempre rigorosas, podem apresentar uma visão das ideias relacionadas ao conceito de função que são mais presentes na 
compreensão desse conceito pelos estudantes. As demais questões da atividade devem fornecer dados que auxiliem na interpretação da definição de função apresentada por esses estudantes.

Essa primeira questão foi deixada em branco por dois estudantes e outros dois estudantes apresentaram respostas confusas, que traziam uma ideia de cálculo ou operação matemática, mas, por não terem dados suficientes, não puderam ser analisadas, como é o caso da resposta a seguir:

"É o que define o resultado de determinada função" (Respostas do Estudante $\mathrm{E}_{1}$ ) "conta matemática" (Resposta do Estudante $\mathrm{E}_{26}$ )

Em doze das demais respostas, os estudantes definiram função utilizando os termos expressão algébrica, fórmula ou equação. Nas respostas dos estudantes há indícios de que "equação" e "expressão algébrica" sejam sinônimas para esses estudantes, pois, como vemos na resposta do Estudante 4, ele atribui à equação a ideia de dependência, o que nos leva a crer que ele se refere a uma expressão algébrica com um termo dependente e uma variável. “É quando uma equação depende de um elemento x para obter algum resultado, quando o resultado de ' $\mathrm{F}$ ' depende do valor numérico de $\mathrm{x}$ " (Estudante $\mathrm{E}_{4}$ )

Seis estudantes definiram função com uma lei de formação, indicando a necessidade de uma lei para que uma relação seja considerada função, o que é uma exigência comum, de acordo com a literatura (CLEMENT, 2001). Uma possível razão para a forte relação entre o conceito de função e sua expressão analítica pode ser o enfoque dado aos cálculos e resolução de expressões algébricas, em especial na forma de igualdades, com o objetivo de descobrir o valor de incógnitas, dados em aulas de matemática ou em outras ciências como a física. Nas respostas a essa questão, três respostas utilizaram exemplos ou termos que invocam aplicações de função ao estudo de fenômenos; na segunda questão do questionário, essa influência torna-se mais clara. Destacamos a resposta de dois estudantes: um que define função como lei de formação, e outro que traz ideias relacionadas a aplicações de função a fenômenos físicos:

"Função é tudo aquilo que tem uma lei de formação" (Estudante $\mathrm{E}_{10}$ )

"É encontrar o valor de uma determinada incógnita dependendo-se de outra (que geralmente é o tempo)" (Estudante $\left.\mathrm{E}_{13}\right)$.

Alguns desses estudantes trouxeram a ideia de lei de formação associada a outros conceitos fundamentais para o estudo de funções como a ideia de variabilidade, dependência e 
relação. Ao todo, oito estudantes utilizaram essas ideias para definir função. Embora não tenham sido utilizados com rigor, esses termos trazem importantes indícios sobre a concepção de função desses jovens que, tendo em sua maioria, exigido uma lei algébrica para que uma relação seja função, compreendem que não é toda expressão algébrica que representa uma função. Houve, ainda, seis estudantes que recorreram a exemplos para explicar sua concepção, como por exemplo, o estudante 24:

"É quando um item tem seu valor variando de acordo com outro. Por exemplo: o preço pago por combustível, que é uma função da quantidade dos litros comprados" (Estudante $\mathrm{E}_{24}$ )

Em contrapartida, apenas cinco estudantes utilizaram a representação gráfica na hora de definir função. Muitas vezes o termo surge como complementar da expressão algébrica da função, ou seja, o estudante associa a representação gráfica a uma função, mas não generaliza as funções a esse registro como ocorre com a expressão algébrica, como na resposta do estudante $\mathrm{E}_{17}$ :

"É uma expressão matemática de onde é possível montar um gráfico em um plano cartesiano" (Estudante $\left.\mathrm{E}_{17}\right)$

As ideias de lógica, sequência e representação de quantidades também foram referenciadas em apenas uma resposta:

"É uma fórmula para identificar uma sequência lógica de algo" (Estudante $\mathrm{E}_{20}$ )

Surpreendeu-nos que apenas dois estudantes definiram função como relação entre conjuntos, embora essa seja a definição mais usual em livros didáticos. Também só duas respostas citaram unicidade de imagem para que a relação possa ser considerada função. Termos usuais como contradomínio, domínio e imagem foram citados apenas uma vez: "Relação de 2 ou mais conjuntos estabelecido por lei de formação" (Estudante $\mathrm{E}_{3}$ ) “Função é dada por domínio e imagem, uma imagem (y) pode ter vários domínios (x), mas o domínio (x) não pode ter mais de uma imagem, se não, não é função, e pode ser perfeitamente ilustrada em um gráfico.” (Estudante $\mathrm{E}_{6}$ )

$2^{a}$ questão: Uma lagarta está rastejando em um pedaço de papel, como mostrado abaixo. Se nós desejarmos determinar a localização da criatura no papel com relação ao tempo, a localização é uma função do tempo? Por que ou por Que não? O tempo pode ser descrito em função da

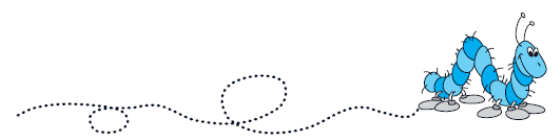


sua localização? Explique.

Essa questão fez parte de uma pesquisa desenvolvida nos Estados Unidos da América pela professora Lisa L. Clement (2001) com estudantes de pré-calculo. A pesquisa revelou que, nessa questão, $60 \%$ dos estudantes pesquisados aplicaram o teste das linhas verticais diretamente na ilustração do problema e consideraram que a situação não era uma função por o gráfico possuir duas imagens. Consideramos esse resultado interessante por revelar que esse grupo de estudantes considerava a trajetória da lagarta como sendo o gráfico da função do deslocamento com o tempo e utilizar o teste das linhas verticais como único critério na hora de avaliar se a situação representa uma função, por isso decidimos colocar essa pergunta em nossa pesquisa e verificar se os estudantes brasileiros de ensino médio participantes da pesquisa teriam uma concepção semelhante sobre o gráfico e a trajetória.

Apenas um estudante deixou essa questão em branco e um outro estudante respondeu apenas "sim", sem apresentar justificativa. Doze estudantes responderam a apenas uma das perguntas desse item ou responderam as perguntas de forma geral. Desses que responderam de forma geral, apenas dois estudantes responderam que não era função, sendo que apenas um apresentou a justificativa mais presente na pesquisa realizada por Clement (2001): que não é função porque o movimento da lagarta no papel desenha voltas e, portanto, possui duas imagens. Observando a imagem do gráfico podemos ver que este estudante utilizou o teste das linhas verticais diretamente na ilustração do trajeto, pois ele marcou quatro pontos justamente nas curvas.

Figura 1: Resposta do estudante $\mathrm{E}_{30}$

20 Uma lagarta está rastejando em um pedaço de papel, como ilustrado abaixo. Se nós desejarmos determinar a localização da criatura no papel com relação ao tempo, a localização é uma função do tempo? Por que ou por que não? O tempo pode ser descrito em função da sua localização? Explique.
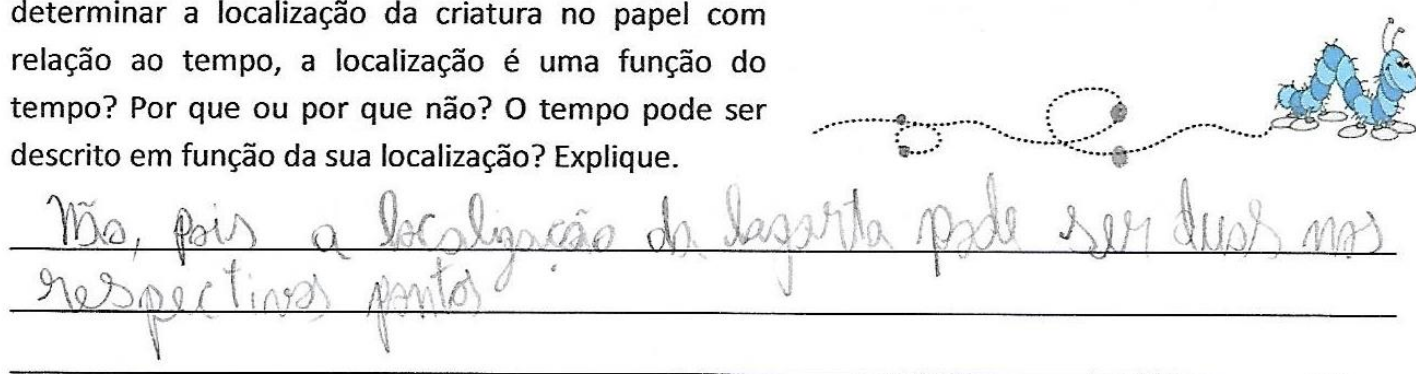

Os outros estudantes que não consideraram função justificaram sua resposta pela irregularidade do movimento, como podemos ver na transcrição a seguir:

"Não, pois isso depende se sua velocidade e direção sejam 'rítmicas"' (Estudante E26) 
Apenas um estudante respondeu que depende, explicando que, para ser função, é necessário que duas localizações não estejam associadas ao mesmo tempo. Esse estudante não havia colocado unicidade na definição de função, mas, por essa segunda questão, fica claro que sabe que é necessário:

"Depende, se a localização for igual para dois tempos diferentes, não pode ser função, mas caso contrário é uma função. Isso se aplica ao tempo também" (Estudante $\mathrm{E}_{4}$ ).

Pela sua resposta percebemos que o estudante não consegue identificar com segurança se nas duas situações do problema há duas imagens. Doze estudantes responderam que sim para ambas as perguntas, sendo que em cinco dessas respostas é imposta a condição de existência de um padrão. Nelas, os estudantes utilizam especificamente termos estudados nas aulas de física, pois exigem movimentação uniforme ou uniformemente variada, ou dados como velocidade. Assim, vemos que, mesmo dentre os estudantes que responderam sim, há a exigência de uma lei para prever outros pontos e localizações e que há uma influência dos estudos da física na análise da situação. Acreditamos que os conhecimentos em outras ciências foi uma das principais razões para a diferença significativa entre os resultados da nossa pesquisa para essa questão e da pesquisa realizada nos Estados Unidos (CLEMENT, 2001).

"Sim, localização é uma função do tempo, porque se o movimento da lagarta é constante ou acelerado tenho equações e gráficos para isso e sim podemos saber o tempo por sua localização, estudamos isso em física" (Estudante $\mathrm{E}_{5}$ ).

Os demais estudantes que responderam sim a ambas as questões argumentaram de forma um tanto vaga, mas em geral, com a ideia de unicidade de imagem. Como eles defendem que há, em ambos os sentidos, uma relação funcional, acreditamos que os estudantes interpretaram a situação como sendo de uma relação bijetora. Um destes estudantes sugeriu a possibilidade se criar um gráfico para associar tempo e localização.

"Sim, pois é possível criar um gráfico utilizando as duas informações (de tempo e espaço)" (Estudante $\mathrm{E}_{17}$ ).

"Sim, porque há uma relação de 2 conjuntos sendo eles localização e tempo, se for dado a localização dá para determinar o tempo e vice-versa" (Estudante $\mathrm{E}_{3}$ ).

Só dois estudantes responderam sim para apenas uma das perguntas. Na resposta do estudante $\mathrm{E}_{20}$, vemos que ele considera que o tempo não é suficiente para saber a localização, possivelmente porque o tempo não indicaria direção ou trajeto. Já o segundo estudante $\left(\mathrm{E}_{27}\right)$ 
argumenta com base na análise de termo dependente e independente, o que pode significar que esse estudante não conhece a possibilidade de função inversa, mas pode ser que só não considere possível nesse problema em particular; contudo, não há uma explicação para impossibilidade de inversão, exceto o termo ser o tempo.

"Não, porque o tempo não vai indicar a localização. Sim, em um determinado tempo ela anda $\mathrm{x}$, no dobro do tempo ela $2 \mathrm{x}$ ". (Estudante $\mathrm{E}_{20}$ )

"Sim, podemos descobrir a localização uma vez que ela é "dependente" do tempo. Não, o tempo é um termo independente" (Estudante $\mathrm{E}_{27}$ ).

Por fim, houve três estudantes que responderam não para ambas as perguntas, e todos argumentaram que não há regularidade na movimentação da lagarta.

"Não, porque seria praticamente impossível estudar a trajetória em relação ao tempo, é extremamente imprevisível o trajeto dela, também não, pois não há um trajeto e tempo capazes para serem medidos" (Estudante $\mathrm{E}_{8}$ ).

$3^{a}$ Questão: Considere as relações a seguir e indique aquelas que acredita serem funções.

a) Em um posto de combustível de Caruaru, a gasolina custa $\mathrm{R} \$ 3,490$ e o álcool $\mathrm{R} \$ 2,839$. O preço a ser pago ao abastecer um carro nesse posto pode ser considerado uma função da quantidade de combustível comprada?

b) Uma equipe de nutricionistas visitou uma escola e, em uma tabela, registrou a altura e o peso de todos os estudantes do Ensino Médio para calcular o Índice de Massa Corpórea, conforme a tabela:

\begin{tabular}{|l|c|c|c|c|c|c|}
\hline Altura (m) & 1,58 & 1,62 & 1,70 & 1,62 & 1,75 & 1,80 \\
\hline Peso $(\mathrm{Kg})$ & 50 & 52 & 56 & 55 & 70 & 61 \\
\hline
\end{tabular}

Considerando os dados do recorte apresentado na tabela, podemos considerar o peso dos adolescentes como uma função da altura?

c) Carlos procurou o gerente do banco no qual ele é correntista e pediu orientação sobre como investir seu dinheiro. O gerente explicou que há uma aplicação com rendimento de $0,08 \%$ ao mês sobre o capital não movimentado na conta nesse período. A relação entre o capital investido e o juro gerado é uma função?

d) Os correios criaram o Código de Endereçamento Postal (CEP) para orientar e acelerar o trabalho de organização e entrega das correspondências. Assim, quando se endereça uma 
carta, deve-se incluir o CEP do destinatário. A relação entre uma casa e o seu CEP pode ser considerada uma função?

e) Uma loja da fábrica de camisetas vende camisetas em varejo e atacado. Para orientar os clientes, ela criou uma tabela de preços: quem comprar até cinco peças pagará $\mathrm{R} \$ 30,00$ por cada, quem comprar de seis a onze peças pagará $\mathrm{R} \$ 25,00$ por peça, e se comprar doze ou mais camisetas pagará apenas $\mathrm{R} \$ 20,00$ a unidade. Podemos dizer que a relação preço e quantidade de camisetas é uma função?

Nessa questão, o estudante deveria avaliar quais situações apresentam relações funcionais. Análise de situações problemas é fundamental nos estudos das aplicações de funções e, novamente, buscamos envolver as ideias da definição de função e concepções comuns. Na primeira situação, apresentamos uma função injetiva aplicada a uma situação classificada como simples, que apresenta a relação entre preço e produto. Pelos dados fornecidos, o estudante pode calcular alguns valores da função. Na segunda, apresentamos uma relação não funcional, por não haver unicidade de imagem, como pode ser visto pela altura de dois estudantes com 1,62 m, que apresentam pesos diferentes. No terceiro item, apresentamos uma relação funcional, mas envolvida em uma situação um pouco mais elaborada, que é o calculo de juros. Na quarta situação, apresentamos uma relação funcional, que não possui uma lei algébrica que a represente. E, na quinta situação, apresentamos uma função com múltiplas leis de formação, mas sendo todas possíveis de serem representadas algebricamente. Assim, podemos analisar alguns elementos presentes na concepção dos estudantes quando aplicados a situações representadas na língua natural.

Apresentaremos a quarta questão antes da análise da terceira, pois na quarta os estudantes explicam o que os levou a classificar os itens da terceira questão com sendo ou não função. Assim, acreditamos que a análise conjunta pode favorecer a compreensão das respostas dos estudantes.

$4^{a}$ Questão: Das relações apresentadas na questão anterior, alguma não é função? Em caso afirmativo, justifique e/ou explique se seria possível transformá-la em função modificando alguma informação do enunciado.

Nessa questão, questionamos o porquê das relações não serem funções e a possibilidade de transformá-las em funções por meio do acréscimo de informações questionou-se sobre essa possibilidade de transformação admitindo-se que alguns estudantes 
pudessem ter utilizado conhecimentos empíricos para interpretar os problemas e que, portanto, um enunciado mais aberto forneceria mais dados sobre o pensamento e critérios adotados pelos estudantes para avaliar cada situação.

Nenhum estudante deixou a terceira questão em branco. Já a quarta questão foi deixada em branco por seis estudantes, sendo que outros quatro estudantes responderam apenas com "sim” e/ou "não", sem justificar. Os demais, em sua maioria, buscaram responder a segunda questão justificando o porquê de as alternativas que não assinalaram não serem funções. Apenas um estudante indicou as expressões algébricas dos dois casos que considerou função: na função da letra "a", ele indicou os reais positivos como domínio e, na letra "e", escreveu três expressões que, embora não sejam exatas, estavam delimitadas corretamente com base no domínio apresentado no enunciado. Assim, vemos que esse estudante compreende a ideia de domínio.

$\mathrm{Na}$ terceira questão, a situação com maior reconhecimento foi a letra "e", identificada por 30 estudantes, o que é interessante, pois o gráfico que se aproxima mais desse problema foi um dos que teve menor reconhecimento pelos estudantes, possivelmente por ser descontínuo e não poder ser descrito por uma única expressão algébrica. O segundo item com maior número de reconhecimento foi a letra "a", com 27 acertos. A letra "c" foi reconhecida por 26 estudantes.

Essas questões que tiveram maior reconhecimento foram comentadas por poucos estudantes. As treze respostas que não consideraram as relações como função tinham como justificativa comentários meio confusos, que indicavam como um dos maiores problemas a interpretação dos enunciados. Os estudantes não conseguiram identificar as relações claramente ou, com base em seus conhecimentos empíricos, julgaram que não eram funções por não conseguirem calcular valores específicos.

"Letra (a), só colocar o valor que já temos em semelhança em litros comprados." (Estudante $\left.\mathrm{E}_{1}\right)$.

“As letras A e D não podem ser correspondidos por função, porque falta informação para completar o raciocínio." (Estudante $\mathrm{E}_{8}$ ).

As questões que tiveram menor número de marcações foram a letra "b", que de fato não apresenta uma relação funcional, e foi assinalada por 13 estudantes, e a letra "d", que é uma função, mas só foi reconhecida por 8 estudantes.

Na quarta questão, os estudantes justificaram não ser função por não haver uma lei de formação, tanto para a letra "b" quanto para a "d" e, para que fosse uma função, sugeriram considerar o índice de massa corpórea. 
“d) Acho que pelo fato de ter inúmeras cidades e a construção de casas não ser algo uniforme, não poderia transformá-la em função" (Estudante $\mathrm{E}_{10}$ ).

“sim. Não há relação matemática entre o CEP e uma casa. No caso dos alunos deveria ser considerado que todos tivessem o mesmo IMC índice de massa corporal.” (Estudante $\mathrm{E}_{24}$ ).

“Sim, as letras b e d pois não é possível montar uma lei de formação. No 'A' poderia ser mudado a estrutura para por exemplo pessoas da mesma altura tivessem o mesmo peso na $b$ poderia ser estabelecido uma relação peso _ > valor, ou endereço _> valor.” (Estudante $\mathrm{E}_{27}$ )

Ainda sobre a letra "b", outros justificaram através da unicidade e chamaram atenção para a existência de dois pesos diferentes para a mesma altura, como vemos a seguir:

“sim b - o peso da criança não depende da altura, na tabela há duas alturas iguais e pesos diferentes. $\mathrm{d}$ - não pois o CEP não é da casa mas sim da rua." (Estudante $\mathrm{E}_{21}$ ).

"crianças com alturas iguais possuem peso diferente e uma função não tem 2 imagens. d) o numero do CEP é aleatório" (Estudante $\mathrm{E}_{23}$ ).

Analisamos as concepções e ideias matemáticas mais presentes nas respostas dos estudantes nas duas primeiras questões, sendo que em algumas respostas não foi possível identificar nenhuma concepção por terem uma explicação confusa, e nas respostas de alguns estudantes foram identificadas mais de uma ideia fundamental para o conceito de função, sendo assim, não foi realizada uma categorização excludente das respostas. As ideias mais presentes foram:

Lei de formação: Quando os estudantes exigiram a existência de uma lei, em geral algébrica, que possibilite relacionar e determinar a imagem de cada elemento do domínio. Essa concepção de função é condizente com a definição de Euler. É compreensível que os estudantes tenham-na mais fortemente consolidada, tendo em vista que, em geral, essa visão é predominante no processo de ensino, tanto nos exemplos utilizados pelos professores, quanto nos livros didáticos e em outras disciplinas que utilizam o conceito, como é o caso da física.

Variação e dependência: Essas palavras trazem ideias essenciais do conceito de função como uma relação entre dois elementos onde, conforme um é modificado, o outro varia, ou onde há uma dependência entre grandezas. Destacamos, contudo, que nas respostas de alguns estudantes foi observado que a variação da imagem no sentido de mudança é uma exigência para os mesmos, que não consideraram a função constante como uma função. Já a palavra dependência geralmente foi utilizada por estudantes que exigiram uma lei algébrica para descrever a dependência entre as grandezas.

Relação entre conjuntos: Essa concepção é coerente com a definição de função de Dirichlet e do grupo Bourbaki. Contudo, embora a definição seja apresentada no início das 
aulas e na introdução do conceito no livro didático, ela não aparece muito nas respostas dos estudantes. Possivelmente, isso se deve a que, no decorrer das aulas de matemática e de outras ciências que utilizam o conceito de função, essa definição não costume ser invocada para avaliar situações relacionais, como indica a pesquisa de Zuffi e Pacca (2002).

Gráfico: Quando o estudante definiu função como um gráfico, curva ou uma relação que possa ser representada em um plano cartesiano. Essa representação sempre esteve presente durante todo o desenvolvimento do conceito de função, inclusive por Euler, que exigia uma representação algébrica capaz de descrever a curva. Embora esteja presente nos livros didáticos, parece ser pouco utilizada pelos estudantes, que priorizam a representação algébrica.

O gráfico a seguir apresenta a distribuição da frequência dessas ideias nas respostas dos estudantes.

Gráfico 1: Ideias relacionadas a definição de função por estudantes na Língua Natural

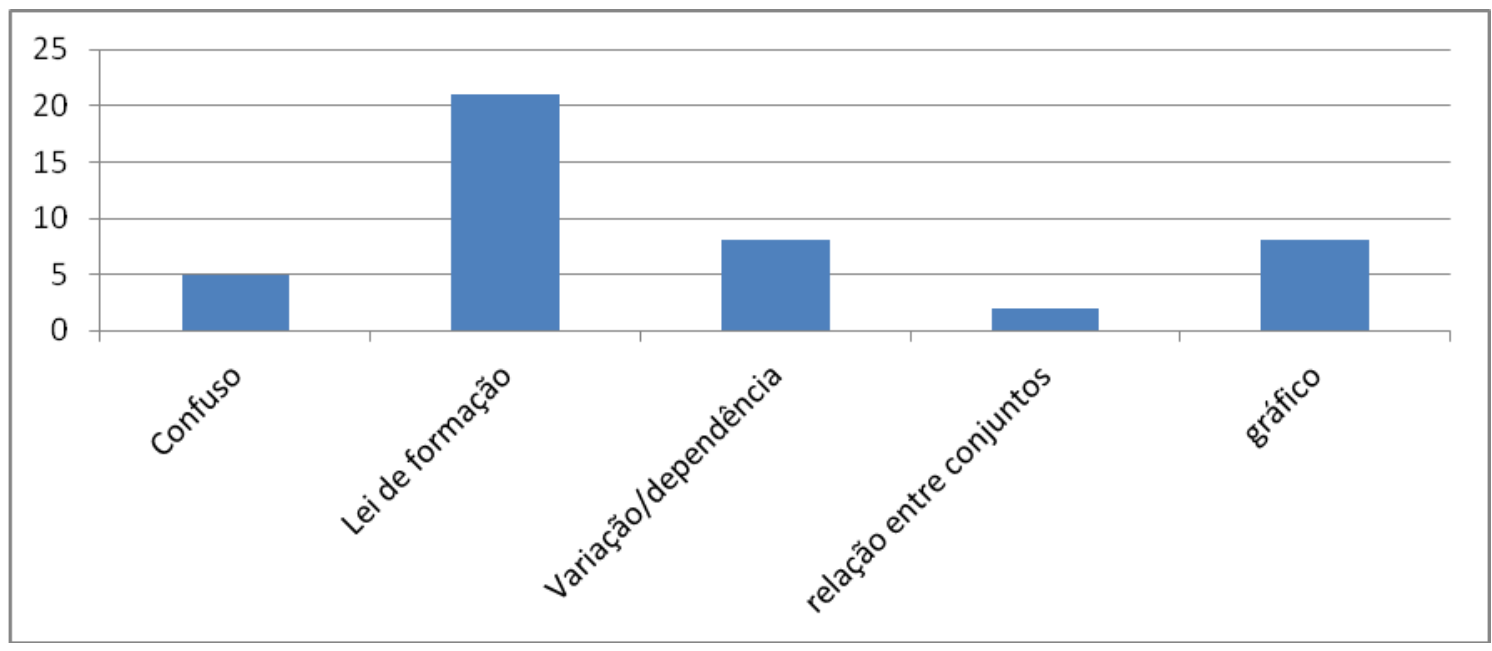

Fonte: os autores

\section{Considerações Finais}

Analisando as concepções de funções mais presentes nas definições dos estudantes foi observado que a maioria dos estudantes considera que para que uma relação seja função ela deve possuir uma expressão algébrica. Essa visão de função como expressão algébrica também esteve presente na história da matemática por praticamente um século e é apontada em outras pesquisas como uma compreensão comum para estudantes tanto da educação básica quanto do ensino superior. Este equívoco é compreensível tendo em vista que as funções estudadas durante quase toda a escolarização são funções com expressões algébricas e que, 
em geral, o ensino é organizado com base na forma da expressão analítica. Como essa representação tem papel central para o desenvolvimento e compreensão das funções, é compreensível que ela esteja presente durante todo o estudo das funções, mas é preciso criar situações que possibilitem a compreensão de que as expressões algébricas são uma forma de representação das funções e não o próprio conceito matemático.

Os resultados indicam que definir o conceito de função foi uma tarefa complexa para os estudantes, que apresentaram respostas incompletas, mas foi possível observar que há uma confusão quanto à representação na forma de expressão algébrica, o que indica a necessidade de discutir mais profundamente esse tópico em aulas ou futuras pesquisas. Quanto às ideias mais presentes nas concepções do conceito de função, observamos que as ideias de lei de formação e dependência são as mais presentes e que, embora poucos estudantes se lembrassem da unicidade na hora de definir função, essa característica é conhecida pela maioria deles, como foi observado em outras questões, sendo necessário mais tempo para uma discussão mais aprofundada sobre essa atividade.

Destacamos que a interpretação da situação com o deslocamento de uma lagarta indica que os estudantes possuem uma compreensão da relação deslocamento e tempo, que não foi restrita à representação gráfica, o que demonstra uma maior clareza sobre a situação problema. Acreditamos que esse resultado se deve ao estudo de situações problemas tanto na matemática como em outras ciências, em especial a física. Assim, sugerimos a realização de novas pesquisas que utilizem situações problemas para abordar as maiores dificuldades dos estudantes envolvendo as suas múltiplas representações como forma de enfrentar essas dificuldades.

\section{Referências}

BRASIL. Ministério da Educação (MEC), Secretaria de Educação Média e Tecnológica (Semtec). PCN + Ensino médio: orientações educacionais complementares aos Parâmetros Curriculares Nacionais - Ciências da Natureza, Matemática e suas Tecnologias. Brasília: MEC/Semtec, 2002.

CLEMENT, L. L. What Do Students Really Know about Functions? In: Mathematics Teacher, vol.94,no 9, p.745-748, Dez. 2001.

DUVAL, R. Mudanças, em curso e futuras, dos sistemas educacionais: Desafios e marcas dos anos 1960 aos anos... 2030!. Trad. MORETTI, M. T.Revemat, v.10, n. 1, Florianópolis: UFSC/MTM/PPGECT, 2015. 
Registros de Representação Semiótica e Funcionamento Cognitivo da Compreensão em Matemática. In: MACHADO, S. D. A. (org.) Aprendizagem em

Matemática, Registros de Representação Semiótica. Campinas: Papirus, p. 11-33, 2010. (Coleção Papirus Educação).

.Registros de representação semiótica e funcionamento cognitivo do pensamento. Trad. MORETTI, M. T.Revemat, v.7, n. 2, Florianópolis: UFSC/MTM/PPGECT, p. 266-297, 2012.

- Semiósis e Pensamento Humano: Registros semióticos e aprendizagens intelectuais (Fascículo I). São Paulo: Livraria da Física, 2009.

Ver e ensinar a matemática de outra forma: Entrar no modo matemático de pensar: os registros de representações semióticas. São Paulo: PROEM, 2011.

MORAES, R. Uma tempestade de luz: a compreensão possibilitada pela análise textual discursiva. Ciência \& Educação, v.9, n. 2, p.191-211, 2003.

MORAES, R; GALIAZZI, M. C. Análise textual discursiva: processo construído de múltiplas faces. Ciência \& Educação, v.12, n.1, p.117-128, 2006.

SOUZA, R. N. S.; MORETTI, M. T. Objeto real versus ideal: consequências na constituição de sistemas semióticos para a aprendizagem intelectual. REnCiMa, v. 6, n. 2, p. 70-85, 2015.

TODOS PELA EDUCAÇÃO. Anuário Brasileiro da Educação Básica: 2016. São Paulo; Moderna, 2016.

ZUFFI, E. M.; PACCA, J. L. A. O conceito de função: seu desenvolvimento histórico e sua apresentação no ensino médio. In.: Anais do III SNHMAT, 1999.

Recebido em 11/04/2017 - Aceito em 24/10/2017 